\title{
Exercise reduces the symptoms of attention-deficit/hyperactivity disorder and improves social behaviour, motor skills, strength and neuropsychological parameters
}

\author{
Carolin Friederike Kamp ${ }^{1}$, Billy Sperlich (billy.sperlich@uni-wurzburg.de) ${ }^{2}$, Hans-Christer Holmberg ${ }^{3}$ \\ 1.Department of Child and Adolescent Psychiatry and Psychotherapy, University of Cologne, Cologne, Germany \\ 2.Department of Sport Science, University of Würzburg, Würzburg, Germany \\ 3.Department of Health Sciences, Swedish Winter Sports Research Centre, Mid Sweden University, Östersund, Sweden
}

\section{Keywords}

ADHD, Children, Exercise, Motor skills, Social behaviour

\section{Correspondence \\ Billy Sperlich, PhD, Department of Sport Science, University of Würzburg, Judenbühlweg 11, \\ 97082 Würzburg, Germany. \\ Tel: +499313181494| \\ Fax: +499313187390| \\ Email: billy.sperlich@uni-wurzburg.de}

\section{Received}

14 August 2013; revised 11 December 2013;

accepted 5 March 2014.

DOI:10.1111/apa.12628
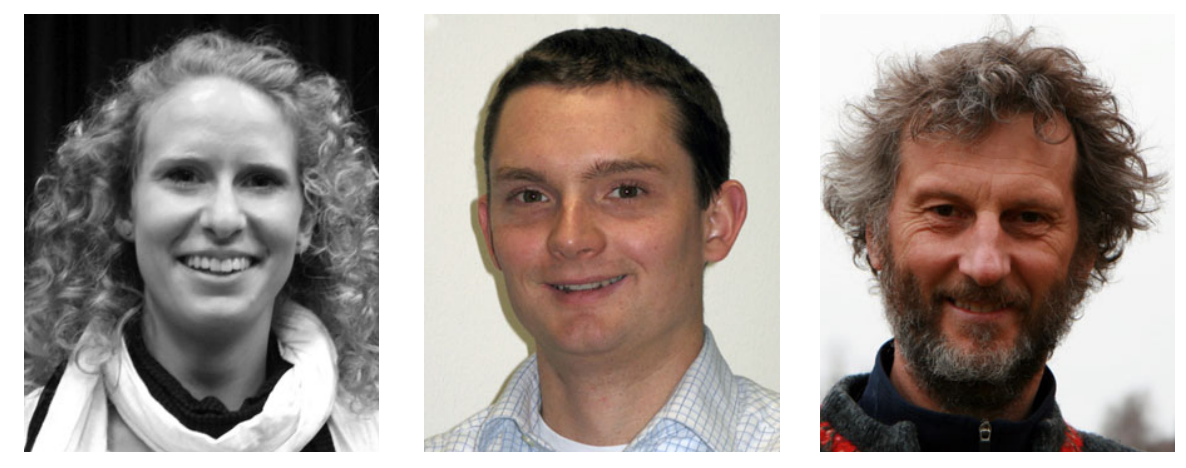

\begin{abstract}
This review summarises research studies on the impact and beneficial effects of different types of exercise on childhood attention-deficit/hyperactivity disorder (ADHD) and provides recommendations for the scientific and therapeutic communities.

Conclusion: Although the design and the exercise interventions featured in these studies varied considerably, all showed that exercise reduced the symptoms of ADHD and led to improvements in social behaviour, motor skills, strength and neuropsychological parameters.
\end{abstract}

\section{INTRODUCTION}

With a worldwide prevalence of 5.3\% (1), attention-deficit/ hyperactivity disorder (ADHD) is diagnosed in $2-6 \%$ of preschool children (2) and 6-13\% of adolescents (3), being more common in boys $(7.9 \%)$ than girls (1.8\%) (4). The typical characteristics of this disorder include inattention, hyperactivity and impulsiveness (5). The associated limitations in cognitive, psychosocial and emotional competence impair mental well-being, disturb familial and academic environments, cause psychological strain and result in a low healthrelated quality of life (4). Both environmental and genetic factors appear to be involved in the aetiology of ADHD (6).

Pharmaceutical treatment of ADHD-related symptoms is commonly based on administration of methylphenidate, atomoxetine and amphetamines. Methylphenidate, a psychostimulant, reduces reuptake of dopamine, thereby enhancing the free level of this neurotransmitter in the pre-frontal cortex. Atomoxetine selectively inhibits reuptake of norepinephrine and amphetamines influences the dopamine system in such a way as to improve resistance to fatigue and elevate mood. The major drawbacks of such drug treatment include the relatively high cost, the dose-dependent efficiency, the unknown long-

\section{Key notes}

- This literature review summarises the effects of exercise on symptoms related to attention-deficit/hyperactivity disorder (ADHD).

- It looks at the effects of various types of exercise on physiological, psychological and neurological parameters, as well as the cardinal and behavioural symptoms associated with ADHD.

- We conclude that all types of exercise employed in the studies reduced the symptoms of ADHD without causing undesirable side effects. 
term side effects and the fact that the medication only addresses symptoms, not the cause.

Other approaches applied in treating children with ADHD include psychotherapy (7), psychoeducation (7), neurofeedback (8), multimodal interventions (9) and numerous forms of physical exercise (10). The types of exercise used in this context to date include combined postural, respiratory and meditation training by yoga (11), games designed to improve cooperation (12), guided walks (13-15), submaximal (16) and maximal (17) cycling, athletic training such as aerobic exercise (18) and skipping rope (19) and different ball games, e.g. basketball and soccer (18). Because of the wide variety of methods (with diverse types of exercises of differing intensity, duration and frequency, differing numbers of boys and girls of various ages, including various types and doses of medication) involved in such studies a comparison is difficult.

In this brief literature review concerning treatment of children with ADHD using exercise, we attempt to (i) summarise available and relevant data, (ii) document the effectiveness of the varying types of exercise, (iii) discuss the physiological, psychological and neurological benefits, along with changes in the typical behavioural symptoms of ADHD and (iv) provide practical recommendations for the scientific and therapeutic communities.

\section{METHODS}

During the period of December 2012 to January 2013, we performed computerised literature searches in PubMed, MEDLINE and SportDiscus using the following mesh terms: 'ADHD', 'attention-deficit/hyperactivity disorder', 'exercise' along with the keywords 'physical activity', 'training', 'movement', 'child', 'youth', 'adolescent' and 'boy'. In addition, we searched the literature manually for additional articles about therapy of ADHD.

\section{Inclusion and exclusion criteria}

The inclusion and exclusion criteria are summarised in Table 1.

We included any type of study - blinded or not, randomised or not, group or individual intervention, with both boys and/or girls as subjects - of more than 5 days in duration. Investigations in which children with ADHD were treated as a subgroup of children with mental problems were excluded. We included all outcomes for children participating in an exercise-based intervention.

The flow diagram in Figure 1 illustrates our search strategy and the subsequent steps of exclusion based on these pre-defined criteria.

\section{RESULTS}

All data regarding background characteristics of the participants, characteristics of the exercise interventions employed, overview of the protocols and major findings of the studies, methodological approaches and primary outcomes as well as an overview of the studies excluded and the specific reasons for exclusion are presented in Tables 2-3 and S1-S3.

\begin{tabular}{|c|c|}
\hline Inclusion criteria & Exclusion criteria \\
\hline Peer reviewed & Unpublished data \\
\hline Participants' $<14$ years of age & Animal studies \\
\hline $\begin{array}{l}\text { Participants diagnosed with ADHD, } \\
\text { both, boys and girls }\end{array}$ & $\begin{array}{l}\text { Studies focusing on } \\
\text { comorbidities }\end{array}$ \\
\hline $\begin{array}{l}\text { Studies involving any kind of physical } \\
\text { activity or exercise with children } \\
\text { with ADHD }\end{array}$ & $\begin{array}{l}\text { Retrospective interviews } \\
\text { Case scenarios and reports }\end{array}$ \\
\hline $\begin{array}{l}\text { A minimum of } 2 \text { training sessions } \\
\text { per week, } 5 \text { such sessions in all, } \\
\text { with a minimal duration of } 5 \text { days }\end{array}$ & $\begin{array}{l}\text { Letters of opinion; } \\
\text { Reviews }\end{array}$ \\
\hline Written in English or with English abstract & $\begin{array}{l}\text { ADHD as a subgroup of } \\
\text { children with mental problems }\end{array}$ \\
\hline $\begin{array}{l}\text { Assessment of the effects of the } \\
\text { activity on the symptoms of ADHD } \\
\text { (inattention, hyperactivity, impulsivity), } \\
\text { as well as other physiological, } \\
\text { neurological, cognitive function } \\
\text { and/or psychological parameters } \\
\text { before, during and/or after the } \\
\text { intervention. }\end{array}$ & $\begin{array}{l}\text { All types intervention not } \\
\text { related to endurance type of } \\
\text { exercise (such as eurhythmy, } \\
\text { sensomotoric training) }\end{array}$ \\
\hline $\begin{array}{l}\text { All types of trial or intervention } \\
\text { (group and individual intervention) }\end{array}$ & \\
\hline Publication not older than 10 years & \\
\hline
\end{tabular}

\section{Description of the methodology}

In all of the studies included, the subjects were selected and diagnosed professionally by a paediatrician. The participants in the investigation by Kang et al. (19) were divided randomly into groups; whereas those studied in the study by Haffner et al. (11) were assigned randomly employing a cross-over design. Taylor and Kuo (15) conducted individual guided walks (for a period of 30 days) as single-blind controlled trials, with each subject acting as his/her own control.

Number, age, gender and medication of the participants The background characteristics of the participants involved in the studies analysed are summarised in Table 2.

Two of these studies $(18,19)$ included a control group, while in another case the participants served as their own controls (15). The investigation of yoga training versus active games involved a cross-over design (11). Only Gapin and Eitner (13) provided information about their control group in their examination of the effects of walking. In all cases, all subjects were seven to 13.8 years old. Only Taylor and Kuo (15) and Verret et al. (18) included both boys and girls. The degree and type of medication varied widely.

\section{The type, intensity, duration and frequency of exercise and length of the intervention}

As documented in Table 3, the nature of the exercise intervention employed in these studies on children with ADHD varied widely. 


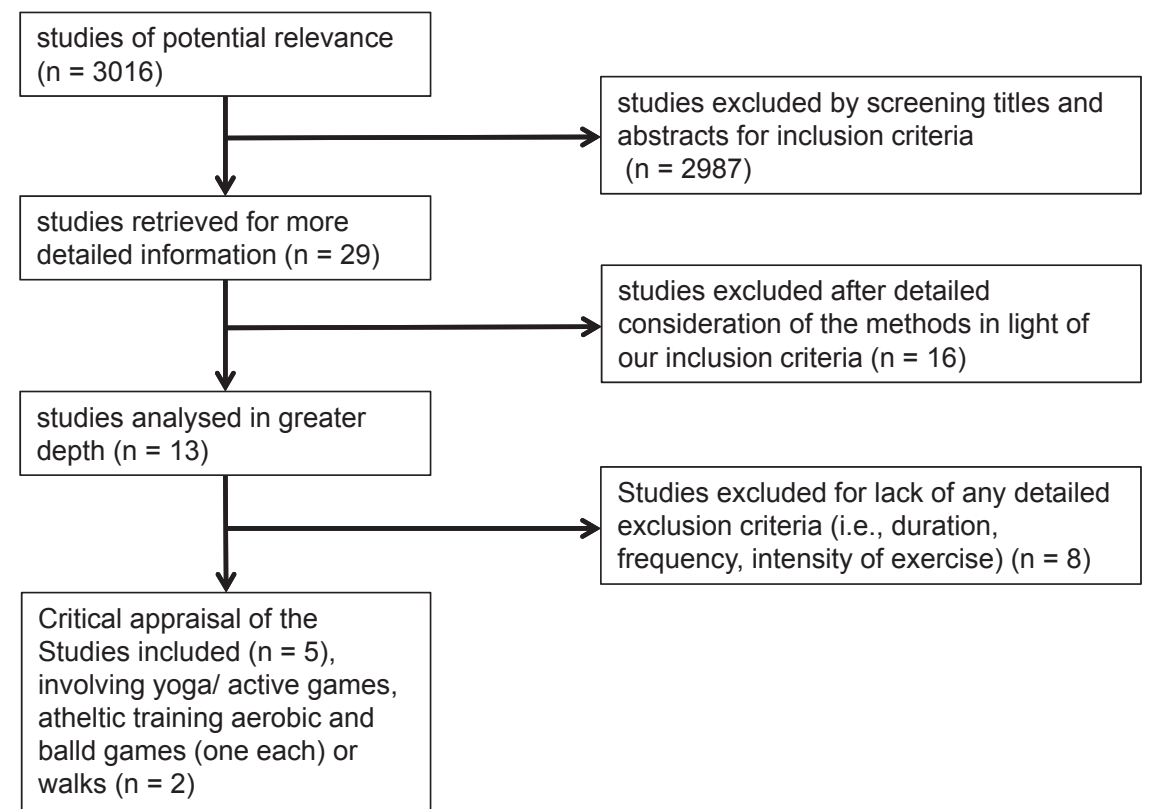

Figure 1 The process of study selection illustrating application of the inclusion and exclusion criteria.

Table 2 Background characteristics of the participants in the studies analysed

\begin{tabular}{|c|c|c|c|c|}
\hline Reference & $\mathrm{N}$, sex & $\begin{array}{l}\text { Mean or range of } \\
\text { age [years] }\end{array}$ & Type of ADHD & Medication \\
\hline Haffner et al. (11) & $19(13$ ठิ, 7 우) & $8-11$ & & 8 medicated \\
\hline \multirow[t]{4}{*}{ Taylor/Kuo (15) } & $17(150,2$ 우 $)$ & $7-12$ & $6 \mathrm{ADD}$ & $56 \%$ used medication daily \\
\hline & & & 10 ADHD (all types) & $19 \%$ only on weekdays \\
\hline & & & $56 \%$ without comorbidities & $31 \%$ not at all \\
\hline & & & & $\begin{array}{l}\text { No medication on the day of } \\
\text { intervention. }\end{array}$ \\
\hline \multirow[t]{6}{*}{ Gapin/Etnier (13) } & $18 \hat{~}$ & $8-12$ & 5 hyperactive impulsive & $\begin{array}{l}\text { Stimulants, } 15 \text { daily and } 3 \text { only } \\
\text { on weekdays }\end{array}$ \\
\hline & & $10.6 \pm 1.5$ & 2 inattentive & \\
\hline & & & 8 combined type & \\
\hline & & & 2 not reported & \\
\hline & & & $45 \%$ with and & \\
\hline & & & $55 \%$ without comorbidities & \\
\hline \multirow[t]{2}{*}{ Kang et al. (19) } & Control group (education) $(n=13,01)$ & $8.6 \pm 1.2$ & & $\begin{array}{l}\text { Both groups were taking } 10-40 \mathrm{mg} \\
\text { methylphenidate/day }\end{array}$ \\
\hline & Intervention group (exercise) $\left(n=15,0^{\wedge}\right)$ & $8.4 \pm 0.9$ & & \\
\hline \multirow[t]{2}{*}{ Verret et al. (18) } & Intervention group (exercise): $(10,9 \hat{0}, 1$ 甲) & $9.1 \pm 1.1$ & Hyperactive impulsive & 30\% medicated \\
\hline & Control group (no exercise): $(11,10 \hat{\delta}, 1$ q) & $13.8 \pm 1.7$ & & All medicated \\
\hline
\end{tabular}

$\hat{0}=$ boys $;+$ = girls; $\mathrm{ADD}=$ Attention Deficit Disorder; ADHD = Attention-Deficit/Hyperactivity Disorder.

The values presented are ranges or means \pm SD.

\section{Effects of exercise on the characteristic symptoms of ADHD}

Yoga training attenuated the characteristic symptoms of ADHD significantly, especially in combination with unspecified medication (11). In this cross-over intervention, therapeutic efficiency was higher when active games were performed prior to yoga training rather than vice versa. With medicated participants (methylphenidate), athletic training, including aerobic and goal-directed exercise and skipping rope, ameliorated symptoms to a greater degree than training of self-control, although both groups showed improvement (19). Following aerobic muscular exercise and training of motor skills, the medicated group was less impulsive and demonstrated fewer attentional and cognitive problems (18). 


\begin{tabular}{|c|c|c|c|c|c|}
\hline Reference & Intensity & Type & $\begin{array}{l}\text { Duration of } \\
\text { each session }\end{array}$ & $\begin{array}{l}\text { Frequency } \\
\text { of sessions }\end{array}$ & $\begin{array}{l}\text { Length of the } \\
\text { intervention }\end{array}$ \\
\hline Haffner et al. (1 1) & Low-moderate & $\begin{array}{l}\text { Yoga (postural, respiratory and } \\
\text { meditation training) in } \\
\text { comparison to active games }\end{array}$ & $1 \mathrm{~h}$ & $2 \times /$ week & 8 weeks \\
\hline Taylor/Kuo (15) & Low-moderate & $\begin{array}{l}\text { Guided walking in an urban } \\
\text { park, downtown or } \\
\text { residential area }\end{array}$ & $20 \mathrm{~min}$ & $1 \times /$ day & 30 day \\
\hline Gapin/Etnier (13) & Moderate & Walks & & $1 \times /$ day & 5 day \\
\hline Kang et al. (19) & Moderate-high & $\begin{array}{l}\text { Athletic (aerobic exercise, } \\
\text { goal-directed exercise, } \\
\text { skipping rope) vs. self-control } \\
\text { training (education) }\end{array}$ & $90 \mathrm{~min}$ & $2 \times /$ week & 6 weeks \\
\hline Verret et al. (18) & $\begin{array}{l}\text { Moderate-high } \\
\text { (77\% of maximal } \\
\text { heart rate) }\end{array}$ & $\begin{array}{l}\text { Aerobic training of muscular and } \\
\text { motor skills (basketball, soccer, } \\
\text { exercise stations, tag and ball games) }\end{array}$ & $45 \mathrm{~min}$ & $3 \times /$ week & 10 weeks \\
\hline
\end{tabular}

\section{Effects of exercise on social behaviour}

Walking at moderate intensity attenuated inhibition in boys (13), while athletic training, especially in combination with unspecified medication, enhanced social skills and cooperativeness (19). Verret et al. (18) observed less anxiety depression and fewer social problems after an intervention involving aerobic training of muscular and motor skills.

\section{Effects of exercise on strength and motor skills}

Aerobic training of muscular and motor skills led to better locomotion and motor skills, as well as greater muscular capacity (18).

\section{Effects of exercise on neuropsychological measures}

Guided walks improved concentration and walks in the park were considered more enjoyable than those in a residential or downtown area (15). These authors note that the effect of such walks in the park on concentration was roughly equal to the maximal effect of two doses of typical ADHD medications. Memory and processing speed were enhanced after 5 days of walking (13). These investigators attributed the improved performance on the Tower of London planning task to more rapid execution times. They associated physical activity with improved executive function and concluded that moderate-to-vigorous physical activity (MVPA) is a predictor of significantly improved planning.

Athletic training improved speed of processing, as well as indicators of intelligence (19). Moreover, in this case the intervention group exhibited enhanced attention, especially visual attention, and speed of processing. The level of information processing was improved by moderate-to-highintensity aerobic training of muscular and motor skills (18).

\section{DISCUSSION}

The major findings of this highly focused review of published reports on the effects of exercise on symptoms of ADHD are the following: First, the study designs (number, age, gender and medication of participants) and exercise modalities (type, intensity, duration and frequency of exercise and length of the intervention) employed varied significantly. Secondly, the characteristic symptoms of ADHD were attenuated by all of the exercise interventions, and measures of social behaviour, motor skills, strength and neuropsychological measures were improved. Furthermore, no side effects were reported.

Because we only analysed interventions lasting one to 10 weeks here, we can draw no conclusions concerning the effects of longer programs. We refrained from analysing interventions involving only one session each week, since we believe that this is insufficient to induce any sustainable response. Unfortunately, some of the investigations considered here did not include a control group and in most cases mean values and standard deviations were not presented, so that effect sizes could not be calculated. Because of the small sample sizes, lack of control groups and varying nature of exercise, no general conclusions about the effectiveness of exercise for treatment of ADHD can be drawn.

In addition, since with the onset of puberty, hormones that influence strength and strength-related skills (motor skills) are released, we did not analyse studies involving children older than 13 and can therefore not say anything about adolescents. Moreover, potential differences between boys and girls are difficult to evaluate on the basis of the interventions included here. Such sex differences may be important, since ADHD is four times as common among men $(7.9 \%)$ than women $(1.8 \%)$ (4), which also explains why most investigations focus on boys. Only three of our studies also involved girls $(11,15,18)$ and none took hormonal development into consideration.

It should also be noted that the participants we analysed were taking different types (stimulants such as methylphenidate or amphetamine or non-stimulants like atomoxetine) and doses of medication. Although Haffner et al. (11) and Kang et al. (19) did observe that exercise was more efficient 
in attenuating symptoms in medicated participants, the correlation between exercise and ADHD medication obviously requires further examination.

The only other review on the impact of physical activity and exercise on children with ADHD currently available [Gapin et al. (10)] also concludes that exercise exerts positive impacts on behavioural symptoms and cognitive performance. These authors state that additional professional physiological, psychological and neurological research in this area is required. However, they do not critically analyse the characteristics of the participants, nature of exercise or various parameters measured, methodological differences that all complicate arriving at general conclusions.

In the five reports considered here, characteristic symptoms were assessed with five different tests, social behaviour with four, fitness and motor skills with six different approaches and neuropsychological impact with three. Neurophysiological parameters (16), the startle eye blink response (ASER) [Tantillo et al. (14)] and quality of sleep [Tantillo et al. (14)] were all examined in one study each. Nonetheless, as summarised in Tables 2-3 and S1, regardless of the nature of the exercise or outcome examined, exercise exerted beneficial effects in all cases.

Of special interest in this context is the demonstration by Haffner et al. (11) that active games followed by yoga training resulted in greater improvement in symptoms than when the order of these interventions was reversed.

A key question involves the impact of intensity, frequency and duration of exercise on gene expression and/or protein synthesis. Wigal et al. (16) observed that children with ADHD of the combined type exhibit smaller increases in serum levels of catecholamines in response to acute exercise than do healthy, aged-matched controls. These authors therefore proposed that ADHD is associated with a catecholamine dysfunction involving the hypothalamicpituitary axis that results in elevated cerebral levels of dopamine following a single session of exercise (10). At present, we cannot conclude which type of exercise is most beneficial for the characteristic symptoms of ADHD. Potentially, both the amount and regularity of training and the duration of the intervention may play crucial roles, perhaps by altering gene expression and/or protein synthesis.

The number of studies included in this literature review is relatively small. However, as a result of our systematic use of inclusion and exclusion criteria, these studies all involved interventions lasting longer than 5 days. Including shorter interventions would have potentially resulted in misinterpretation of the effects of exercise on symptoms related to ADHD. We are aware that the nature and length of the interventions analysed here are heterogeneous, but they all attenuated symptoms related to ADHD, even though we cannot conclude which type is most effective. Most of the studies were on boys, so we cannot draw conclusions concerning girls. In all cases the intensity of exercise was from low to moderate, so the influence of high-intensity exercise interventions remains to be explored. Finally, the variety of diagnostic tools employed renders direct comparisons between these investigations difficult.

\section{Considerations for future research and therapeutic strategies}

Our present analysis reveals that various types of either moderate- and/or high-intensity exercise improve psychosocial and physiological parameters related to ADHD in children, with no undesirable side effects being reported. Unfortunately, it is not yet known which type of exercise is most beneficial. With interventions of 1-10 weeks involving at least two sessions of moderate exercise each week, yoga, walking and ball and activity games all appear to attenuate the characteristic symptoms of ADHD.

From a practical point of view, high-intensity physical activity may represent an interesting alternative to pharmaceutical treatment of ADHD for the following reasons: First, high-intensity exercise is less time consuming than submaximal exercise and is thereby of increasing interest to other groups of individuals with a particular focus on health (20-23). Secondly, the natural movements of children are characterised by spontaneous, short-term high-intensity activity, with repetitive bouts of sprints interspersed with short periods of recovery (24). Moreover, pre-pubertal children maintain performance without substantial fatigue to a greater extent than adults (24). Furthermore, repetitive movement at a velocity close to or even higher than the maximal aerobic speed, separated by short periods of recovery, improves endurance in children (25-28). Although continuous aerobic activity has been more extensively characterised and is a more established mode of training, high-intensity intermittent training may enhance both aerobic and anaerobic performance in children even more effectively.

\section{CONCLUSION}

The present review summarises the impact of exercise interventions (1-10 weeks in duration with at least two sessions each week) on parameters related to ADHD in 7to 13-year-old children. We may conclude that all different types of exercise (here yoga, active games with and without the involvement of balls, walking and athletic training) attenuate the characteristic symptoms of ADHD and improve social behaviour, motor skills, strength and neuropsychological parameters without any undesirable side effects. Available reports do not reveal which type, intensity, duration and frequency of exercise is most effective in this respect and future research focusing on this question with randomised and controlled long-term interventions is warranted.

\section{ACKNOWLEDGEMENTS}

The authors have no conflicts of interest directly related to this article to declare. No external funding was required or provided. 


\section{References}

1. Polanczyk G, de Lima MS, Horta BL, Biederman J, Rohde LA. The worldwide prevalence of ADHD: a systematic review and metaregression analysis. Am J Psychiatry 2007; 164: 942-8.

2. Schmidt S, Petermann F. Developmental psychopathology: attention Deficit Hyperactivity Disorder (ADHD). BMC Psychiatry 2009; 9: 58.

3. Skounti M, Philalithis A, Galanakis E. Variations in prevalence of attention deficit hyperactivity disorder worldwide. Eur J Pediatr 2007; 166: 117-23.

4. Schlack R, Holling H, Kurth BM, Huss M. [The prevalence of attention-deficit/hyperactivity disorder (ADHD) among children and adolescents in Germany. Initial results from the German Health Interview and Examination Survey for Children and Adolescents (KiGGS)]. Bundesgesundheitsblatt Gesundheitsforschung Gesundheitsschutz 2007; 50: 827-35.

5. Association AP. Diagnostic and statistical manual of mental disorders DSM-IV-TR. 4 ed. Washington, DC: American Psychiatric Association (APA), 2000.

6. Akutagava-Martins GC, Salatino-Oliveira A, Kieling CC, Rohde LA, Hutz MH. Genetics of attention-deficit/ hyperactivity disorder: current findings and future directions. Expert Rev Neurother 2013; 13: 435-45.

7. Serrano-Troncoso E, Guidi M, Alda-Diez JA. Is psychological treatment efficacious for attention deficit hyperactivity disorder (ADHD)? Review of non-pharmacological treatments in children and adolescents with ADHD. Actas Esp Psiquiatr 2013; 41: 44-51.

8. Holtmann M, Stadler C, Leins U, Strehl U, Birbaumer N, Poustka F. [Neurofeedback for the treatment of attentiondeficit/hyperactivity disorder (ADHD) in childhood and adolescence]. Z Kinder Jugendpsychiatr Psychother 2004; 32: 187-200.

9. Young S, Amarasinghe JM. Practitioner review: nonpharmacological treatments for ADHD: a lifespan approach. $J$ Child Psychol Psychiatry 2010; 51: 116-33.

10. Gapin JI, Labban JD, Etnier JL. The effects of physical activity on attention deficit hyperactivity disorder symptoms: the evidence. Prev Med 2011; 52(Suppl 1): S70-4.

11. Haffner J, Roos J, Goldstein N, Parzer P, Resch F. [The effectiveness of body-oriented methods of therapy in the treatment of attention-deficit hyperactivity disorder (ADHD): results of a controlled pilot study]. Z Kinder Jugendpsychiatr Psychother 2006; 34: 37-47.

12. Jensen PS, Kenny DT. The effects of yoga on the attention and behavior of boys with Attention-Deficit/hyperactivity Disorder (ADHD). J Atten Disord 2004; 7: 205-16.

13. Gapin J, Etnier JL. The relationship between physical activity and executive function performance in children with attentiondeficit hyperactivity disorder. J Sport Exerc Psychol 2010; 32: 753-63.

14. Tantillo M, Kesick CM, Hynd GW, Dishman RK. The effects of exercise on children with attention-deficit hyperactivity disorder. Med Sci Sports Exerc 2002; 34: 203-12.

15. Taylor AF, Kuo FE. Children with attention deficits concentrate better after walk in the park. J Atten Disord 2009; 12: 402-9.

16. Wigal SB, Nemet D, Swanson JM, Regino R, Trampush J, Ziegler MG, et al. Catecholamine response to exercise in children with attention deficit hyperactivity disorder. Pediatr Res 2003; 53: 756-61.

17. Medina JA, Netto TL, Muszkat M, Medina AC, Botter D, Orbetelli R, et al. Exercise impact on sustained attention of ADHD children, methylphenidate effects. Atten Defic Hyperact Disord 2010; 2: 49-58.

18. Verret C, Guay MC, Berthiaume C, Gardiner P, Beliveau L. A physical activity program improves behavior and cognitive functions in children with ADHD: an exploratory study. J Atten Disord 2012; 16: 71-80.

19. Kang KD, Choi JW, Kang SG, Han DH. Sports therapy for attention, cognitions and sociality. Int J Sports Med 2011; 32: 953-9.

20. Shiraev T, Barclay G. Evidence based exercise - clinical benefits of high intensity interval training. Aust Fam Physician 2012; 41: 960-2.

21. Guiraud T, Nigam A, Gremeaux V, Meyer P, Juneau M, Bosquet L. High-intensity interval training in cardiac rehabilitation. Sports Med 2012; 42: 587-605.

22. Sijie T, Hainai Y, Fengying Y, Jianxiong W. High intensity interval exercise training in overweight young women. J Sports Med Phys Fitness 2012; 52: 255-62.

23. Sartor F, de Morree HM, Matschke V, Marcora SM, Milousis A, Thom JM, et al. High-intensity exercise and carbohydratereduced energy-restricted diet in obese individuals. Eur J Appl Physiol 2010; 110: 893-903.

24. Massicotte DR, Macnab RB. Cardiorespiratory adaptations to training at specified intensities in children. Med Sci Sports Exerc 1974; 6: 242-6.

25. Sperlich B, Zinner C, Heilemann I, Kjendlie PL, Holmberg HC, Mester J. High-intensity interval training improves $\mathrm{VO}$ (2peak), maximal lactate accumulation, time trial and competition performance in 9-11-year-old swimmers. Eur J Appl Physiol 2010; 110: 1029-36.

26. Armon Y, Cooper DM, Flores R, Zanconato S, Barstow TJ. Oxygen uptake dynamics during high-intensity exercise in children and adults. J Appl Physiol 1991; 70: 841-8.

27. Fawkner SG, Armstrong N, Potter CR, Welsman JR. Oxygen uptake kinetics in children and adults after the onset of moderate-intensity exercise. J Sports Sci 2002; 20: 319-26.

28. Williams CA, Carter H, Jones AM, Doust JH. Oxygen uptake kinetics during treadmill running in boys and men. $J \mathrm{Appl}$ Physiol 2001; 90: 1700-6.

\section{SUPPORTING INFORMATION}

Additional Supporting Information may be found in the online version of this article:

Table S1 Overview of the protocols and major findings of the studies analysed.

Table S2 Methodologies and primary outcomes of included studies.

Table S3 Overview of excluded studies with specific reason for exclusion. 